\section{Cahiers de Narratologie}

Analyse et théorie narratives

$7 \mid 1996$

Mélanges espace \& temps

\title{
L'espace de la ville dans la poétique d'Alejo Carpentier ou la valorisation des contextes urbains latino-américains
}

Fabrice Parisot

\section{CpenEdition}

Journals

Édition électronique

URL : https://journals.openedition.org/narratologie/11780

DOI : 10.4000/narratologie. 11780

ISSN : 1765-307X

Éditeur

LIRCES

Édition imprimée

Date de publication : 1 janvier 1996

Pagination : 63-83

ISSN : 0993-8516

\section{Référence électronique}

Fabrice Parisot, «L'espace de la ville dans la poétique d'Alejo Carpentier ou la valorisation des contextes urbains latino-américains », Cahiers de Narratologie [En ligne], 7| 1996, mis en ligne le 27 avril 2021, consulté le 05 mai 2021. URL : http://journals.openedition.org/narratologie/11780 ; DOI : https://doi.org/10.4000/narratologie.11780

Ce document a été généré automatiquement le 5 mai 2021.

Article L.111-1 du Code de la propriété intellectuelle. 


\title{
L'espace de la ville dans la poétique d'Alejo Carpentier ou la valorisation des contextes urbains latino- américains
}

\author{
Fabrice Parisot
}

1 La ville est un espace qui fascine. Peintres, écrivains ou cinéastes en ont la plupart du temps fait le décor idéal, parfois idéalisé, de leurs créations, donnant ainsi progressivement naissance à la mythification de bon nombre d'entre elles: Venise, Rome, Paris, Bruges, Dublin, Barcelone, Hollywood, New York, pour n'en citer que quelques unes, en sont de vivants exemples.

2 Or, on aura remarqué que dans cette longue énumération ne figure aucune métropole $\mathrm{du}$ Nouveau Monde. C'est pourquoi le romancier cubain Alejo Carpentier, qui «a toujours eu une haute conscience du rôle qu'est appelée à tenir l'Amérique latine sur la scène universelle " s'est attaché tout au long de sa carrière littéraire à faire en sorte que la ville d'Amérique latine, et plus particulièrement La Havane, accède aussi au rang de grande cité mythique faisant immédiatement surgir chez le lecteur des images bien précises.

3 Aussi, afin que la ville du continent sud-américain puisse être perçue ainsi à l'avenir, il s'est efforcé, notamment dans ses nombreux essais sur la théorie de la littérature, de mener une réflexion sur les contextes urbains et de proposer, en prenant La Havane comme réfèrent, une poétique de la ville destinée à inciter les jeunes générations de romanciers latino-américains du début des années 60 à créer littérairement leur ville.

4 Partant lui-même de cette théorie, Carpentier a tenté dans ses romans de créer le mythe de la ville latino-américaine et de neutraliser, pour y parvenir, les mythes urbains nord-américains et européens préexistants en les confrontant aux possibilités sous-jacentes de « devenir-mythe » des cités d'Amérique latine. 


\section{Pour une poétique des contextes urbains}

5 Dans ses essais théoriques ou réflexions sur la littérature, Alejo Carpentier a tenté de définir et de développer une poétique de la ville dont puissent tirer avantageusement profit les jeunes écrivains latino-américains afin de faire accéder la ville d'Amérique latine au rang de ville mythique et universelle.

6 La raison de ce soudain intérêt qu'il convient impérativement de porter à l'espace urbain, trouve une explication dans le formidable essor dû à la croissance démographique et au développement économique qu'ont connus certains pays du Nouveau Continent à la fin du XIXème siècle, provocant l'émigration massive des populations vers les grandes métropoles :

"Entretanto las ciudades (caso de Caracas, de México) han conocido un crecimiento fenomenal, con sus consiguientes conflictos ${ }^{1}$."

"Mientras el hombre de Europa nacía, crecía, maduraba entre piedras seculares, edificaciones viejas.... el latinoamericano nacido en los albores de este siglo de prodigiosos inventos, mutaciones, revoluciones, abría los ojos en el ámbito de ciudades que casi totalmente inmovilizadas desde los siglos XVII y XVIII empezaban a agigantarse, a extenderse, a alargarse, a elevarse al ritmo de las mezcladoras de concreto... Parecida a La Habana de Humboldt era todavía la que transité en mi infancia; el México que visité en 1926 era todavía el de Porfirio Diaz; muy semejante aún a la Caracas que describió José Martí fue la Caracas que conocí en 1945. Y de repente he aquí que las amodorradas capitales nuestras se hacen ciudades de verdad (anárquicas en su desarrollo repentino, anárquicas en su trazado, excesivas, irrespetuosas en su afán de demoler para reemplazar) y el hombre nuestro consustanciado con la urbe se nos hace hombre-ciudad. hombreciudad-del-siglo-XX, valga decir : hombre-Historia-del-siglo- $\mathrm{XX}^{2}$."

7 Dire la ville, c'est dès lors faire acte d'historien et s'inscrire en Chroniqueur de la

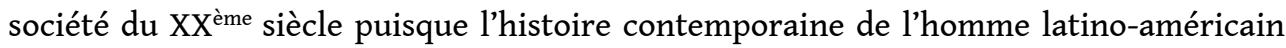
ne semble pas pouvoir être dissocée de l'évolution de la ville et que la ville n'existe que grâce à l'homme. Aussi, Carpentier, prenant La Havane comme référent, s'étonne-t-il et déplore-t-il qu'aucune cité du Nouveau Monde ne soit au cœur des préoccupations des romanciers hispano-américains puisqu'elle semble bien devoir constituer un des enjeux littéraires de cette fin de siècle. C'est pourquoi il allait recommander aux écrivains issus du continent américain d'abandonner le nativisme avec ses plaines et ses forêts pour s'intéresser plus particulièrement à la ville :

"Al ver cuán pocas veces han dado los novelistas cubanos, hasta ahora, con la esencia de La Habana, me convenzo de que la gran tarea del novelista americano de hoy está en inscribir la fisonomía de sus ciudades en la literatura universal, olvidándose de tipicismos y costumbrismos ${ }^{3}$."

8 Certes, passer tout à coup du nativisme à l'écriture de la ville n'est pas une tâche aisée et Carpentier est à ce sujet tout à fait conscient de la difficulté que représente l'effort de révéler une ville plutôt que des montagnes ou des forêts :

"Y que acaso nuestras ciudades por no haber entrado aún en la literatura son más difíciles de manejar que las selvas o las montañas"."

9 Mais il insiste cependant sur l'impérieuse nécessité de faire accéder à présent les cités américaines au rang d'universalité :

"Pero pintar montañas y llanos es más fácil que revelar una ciudad y establecer sus relaciones posibles - por afinidades o contrastes - con lo universal. Por ello, ésa es la gran tarea que se impone ahora al novelista latinoamericano ${ }^{5}$." 
10 L'objectif clairement affiché est dès lors de trouver un point de fixation qui permette d'ancrer dans l'esprit des lecteurs la physionomie des villes américaines afin de les rendre mythiques :

"Hay que fijar la fisonomía de nuestras ciudades $6 . "$

11 Carpentier est en effet totalement convaincu que les métropoles latino-américaines ont elles aussi un rôle prépondérant à tenir en littérature du fait qu'elles offrent à présent, grâce aux formidables mutations qu'elles ont connues, une réalité concrète que l'on a le devoir d'exprimer et de faire connaître car elles sont productrices de signes et de sens :

“...nuestras ciudades están empezando a hablar ahora ${ }^{7} . "$

Pour ce faire, il convient de dire, de faire vivre et de révéler la ville en la narrativisant au moyen d'une savante alchimie verbale qui consiste justement à transformer, à transmuter la réalité citadine en réalité littéraire :

"Hay que dar vida verbal a nuestras ciudades agigantadas.".

13 Il est donc impératif que le romancier abandonne définitivement la campagne pour s'installer à la ville, de préférence dans la capitale, afin de traquer et de révéler les archètypes représentatifs qui permettront justement ce passage au mythe et à l'universel :

"El novelista se traslada del campo a la urbe, a la capital, en busca de arquetipos representativos ${ }^{9} . "$

14 De plus, ces archètypes devraient être relativement faciles à trouver puisque Carpentier - se plaçant désormais dans la position de l'esthète et non plus dans celle de l' historien-sociologue - rappelle avec insistance que les villes d'Amérique latine connaissent depuis un certain nombre d'années un véritable processus de symbioses transculturelles tant au niveau architectural qu'au plan humain. Ce sont précisément ces symbioses que le romancier devra mettre en valeur puisqu'elles font et fondent l'essence même de l'identité latino-américaine :

"Las nuestras (ciudades), en cambio, están, desde hace mucho tiempo, en proceso de simbiosis, de amalgamas, de transmutaciones - tanto en lo arquitectónico como en lo humano - ${ }^{10}$."

15 Ces éléments nés des symbioses successives se trouvent, se retrouvent principalement dans le style même des villes qui, paradoxalement, n'ont pas à proprement parler, selon Carpentier, de style ou qui ont plutôt un style sans style, hérité du mélange des cultures et des civilisations qui se sont succédées sur le continent :

"La gran dificultad de utilizar nuestras ciudades como escenarios de novela está en que nuestras ciudades no tienen estilo... Más o menos extensas... son un amasijo, un arlequín de cosas nuevas y cosas detestables ${ }^{11}$."

"Nuestras ciudades no tienen estilo. Y sin embargo empezamos a descubrir ahora que tienen lo que podríamos llamar un tercer estilo : el estilo de las cosas que no tienen estilo ${ }^{12}$."

Ce troisième style défini comme un style sans style se révèle aux yeux de Carpentier d'une importance capitale car - outre que l'on atteint ici la définition même du baroque américain tel qu'il le conçoit - «à travers les strates de style successif, ce sont en fait les étapes d'une implantation humaine qui sont imprimées dans la pierre ${ }^{13}$. »

17 La tâche du romancier sera donc double : d'un côté, révéler le caractère esthétique des villes latino-américaines et de l'autre, interroger l'Histoire et le passé pour comprendre et expliquer le présent. 


\section{La ville latino-américaine : développement, gigantisme, démesure et poésie}

18 La ville latino-américaine en général est souvent associée dans les récits d'Alejo Carpentier à la notion de bouleversement ${ }^{14}$. Ces bouleversements peuvent être dus soit aux conditions climatiques, soit au vertigineux développement économique né au $\mathrm{XIX}^{\mathrm{x} m e}$ siècle en raison de l'essor de l'industrie concentrée justement dans les zones urbaines, ou bien encore aux agitations politiques.

Ainsi, dans Los pasos perdidos, la description de Caracas qui ouvre le second chapitre met-elle l'accent sur le combat singulier que doit livrer l'homme contre la nature afin d'urbaniser un site particulièrement marécageux et insalubre :

"Durante centenares de años se había luchado contra raíces que levantaban los pisos y resquebrajaban las murallas; pero cuando un rico propietario se iba por unos meses a París, dejando la custodia de su residencia aservidumbres indolentes, las raíces aprovechaban el descuido de canciones y siestas para arquear el lomo en todas partes acabando en veinte días con la mejor voluntad funcional de Le Corbusier ${ }^{15}$."

D'autre part, la ville latino-américaine a connu dès le XIX ${ }^{\mathrm{èm}}$ siècle un fabuleux essor qui a entraîné de profonds bouleversements et qui a parfois contribué à faire de ces nouvelles métropoles de gigantesques ensembles excessivement démesurés. Ainsi, dans El recurso del método, Carpentier évoque non sans ironie les profondes transformations urbaines, conséquences du boom économique dû à la première guerre mondiale : on édifie les premiers gratte-ciel et, dans les quartiers résidentiels, on construit de prétentieuses villas imitant tous les styles européens ou nord-américains :

"Contemplando aquella urbe que le crecía, le crecía, el Primer Magistrado se angustiaba a veces ante la modificación del paisaje ${ }^{16}$."

"El Presidente tenía motivos para estar contento, en aquellos meses, ya que nunca había conocido la Nación una época tan próspera ni tan feliz... Rodeada de selvas milenarias, la capital se había vuelto una moderna selva de andamios, de maderos apuntados al cielo, de grúas en acción, de palas mecánicas, en un perpetuo rechinar de poleas. Las tiendas se ampliaban en una noche, amaneciendo con vitrinas nunca vistas... El teodolito y la lienza transformaban terrenos anegadizos, eriales, potreros de cabras en extensiones divididas que pasaban a llamarse Bagatelle o West Side....

Con ello había nacido el primer rascacielos - cinco pisos con ático - empezándose de inmediato la construcción del Edificio Titán que tendría ocho. Y la vieja ciudad con sus casas de dos plantas, se fue transformando muy pronto en una Ciudad Invisible. Invisible porque pasando de ser horizontal a vertical, no había ojos ya que la vieran y la conocieran. Cada arquitecto, empeñado en la tarea de hacer edificios más altos que los anteriores, sólo pensaba en la estética particular de su fachada.. Y una mañana, la añeja Villa amaneció con la plena conciencia de haberse vuelto toda una señora Capital del siglo $\mathrm{XX}^{17}$."

21 Même la petite ville du Cap décrite dans El reino de este mundo ne semble pas avoir échappé à la modernisation :

"En aquellos años la ciudad había progresado asombrosamente. Casi todas las casas eran de dos pisos, con balcones de anchos alares en vuelta de esquina y altas puertas de medio punto, ornadas de finos alamudes o pernios trebolados ${ }^{18}$."

Enfin, c'est certainement dans La consagración de la primavera que Carpentier offre la meilleure illustration aboutie du profond développement de la ville latino-américaine 
en proposant une description quelque peu satirique de la Caracas des années 50 qui, grâce à l'argent du pétrole, se transforme de façon anarchique et démesurée :

"En cuanto a mí, seguía los acontecimientos con un creciente interés, mientras trataba de entender esta rara ciudad que tenía la virtud de trastrocar todas mis nociones, haciéndoseme, de día en día, más rara, desconcertante, excesiva, teratológica, y hasta repelente, a veces, aunque enigmática, contrastada, misteriosa, difícil de penetrar y tremendamente atractiva a pesar de la anarquía de sus voliciones, porque en ella se asistía, de seguro, a la gestación de algo - de algo específicamente latinoamericano, sólo concebible en una ciudad cuya existencia cotidiana era un siempre renovado happening... Sobre el secular establo de ganadería que había sido Venezuela habíase asistido a una repentina transformación de Diógenes en Rey Midas. Y ese Rey Midas había armado el más extraordinario de los maremagnum urbanístico, soltando sus jaurias de buldozers ${ }^{19}$." journalistiques ${ }^{20}$, est certainement la ville qui l'a le plus fasciné, à tel point qu'il en a souvent fait le cadre même de la plupart de ses romans ${ }^{21}$. Même ses recueils d'essais théoriques sur la littérature évoquent la capitale cubaine et ses vieux quartiers comme dans Tientos y Diferencias par exemple où l'on peut trouver une réflexion sur l'évolution des styles architecturaux qui se sont succédés et mêlés au fil des siècles :

"Y La Habana colonial con sus edificios admirables, ejemplos de majestad y sobriedad arquitectónicas de los siglos XVI y XVIII. Pero junto a ellos los años novecientos trajeron una arquitectura más o menos madrileña, más o menos catalana que en otros días me parecían inadmisibles. Pues bien, desde hace poco, esa arquitectura ha empezado a tener encanto y gracia. Va cobrando carácter y empaque. El tiempo le confirió una relativa vetustez, un aire de época un tanto humilde, patinado, démodé que las inscribe, poéticamente dentro de los caracteres fisonómicos de la ciudad ${ }^{22}$."

"En el Vedado de La Habana zona urbana de la que soy transeúnte infatigable, se entremezclan todos los estilos imaginables: falso helénico, falso romano, falso Renacimiento, falsos castillos de la Loira, falso rococó, falso modern style, sin olvidar los grandes remedos debidos a la ola de prosperidad traída por la primera guerra mundial - remedos a su vez de otras cosas....."

Mais comme le font très justement remarquer Jean Lamore et Marie Hélène Motarella c'est dans La ciudad de las columans, synthèse de ses écrits journalistiques antérieurs, que Carpentier offre la forme la plus achevée de sa réflexion sur La Havane. En effet, « dans 
cet essai sur l'architecture de la ville à travers lequel l'écrivain se propose d'élucider minutieusement les principaux signes qui la composent, Carpentier met en application sa méthode de création littéraire fondée sur une perception nouvelle de la réalité, faite de distanciation et de multiplicité de points de vue et qui débouchent sur une reconstruction de la réalité de sa ville : La Havane vue et révélée par Carpentier ${ }^{24}$. »

La Havane et ses vieux quartiers - c'est-à-dire essentiellement La Havane coloniale -, qu'il nous décrit toujours en piéton, ont sa prédilection car ce sont eux qui l'enchantent. La ville lorsqu'on entre du port, comme le fit jadis Humboldt, séduit le visiteur par son aspect riant et pittoresque :

"El aspecto de La Habana cuando se entra en su puerto es uno de los más rientes y más pintorescos que puedan gozarse en el litoral de la América equinoccial ${ }^{25}$."

Au début de El siglo de las Luces, Carlos aborde la ville de la même façon et contemple la vue d'ensemble qu'elle offre sous le soleil de l'après-midi :

“...el adolescente miraba la ciudad, extrañamente parecida a esta hora de reverberaciones a un gigantesco lampadario barroco cuyas cristalerías verdes, rojas, anaranjadas colorearan una confusa rocalla de balcones, arcadas, cimborrios, belvederes y galerías de persianas.. ${ }^{26 "}$

Enfin, le port de La Havane est, selon les termes mêmes du romancier, un endroit plein de poésie :

"Nada falta al puerto de La Habana de lo que hace la poesía de los más grandes puertos del mundo. $27 "$

31 La Havane, plaque maritime tournante où viennent mouiller tous les bateaux du monde :

"Aquel emporio que todos los barcos del mundo frecuentaban ${ }^{28 .}$." est une ville brillante et lumineuse :

"Una ciudad tan relumbrante como La Habana" colorée et joyeuse :

"Iba según el embadurno de las casas, de lo ocre a lo cenizo, de lo verde a lo morado ${ }^{30}$."

"Los forasteros alababan el color y el gracejo de la ciudad ${ }^{31}$." où se mêlent de subtiles odeurs :

“...quedaron atrás los olores marítimos, barridos por el respiro de vastas casonas repletas de cueros, salazones panes de cera y azúcares prietas, con cebollas de largo tiempo almaceradas, que retoñaban en sus rincones oscuros junto al café verde y al cacao derramado por las balanzas. Todo olía fuertemente en esa hora próxima a un crepúsculo que incendiaría el cielo durante unos minutos : la leña mal prendida y la boñiga pisoteada, la lona mojada de los toldos, el cuero de las talabarterías y el alpiste de las jaulas de canarios colgadas de las ventanas. A arcilla olían los tejados húmedos, a aceite muy hervido las frituras, a fogata en Isla de Especias los tostadores de café con el humo pardo. Pero el tasajo, sin equívoco posible olía a tasajo ; tasajo omnipresente, guardado en todos los sótanos y transfondos cuya acritud reinaba en la ciudad, invadiendo los palacios, impregnando las cortinas.... Como antídoto de tanta cecina presente desembocaba de pronto por el respiradero de una calleja sin salida el noble aroma del tabaco ${ }^{32} . . . "$

"El aliento de los anafes abanicados con una penca, la leña de los fogones, el estupendo salmuerio gris del café en tostadero, el portento aroma de los grandes almacenes de tabaco, el vetiver, la albahaca, la yerbabuena, el nardo ofrecido en los altos portales del Palacio del Aldama, las repentinas presencias del ajo, la naranja agria y el sofrito en vuelta de una esquina, y hasta el acre hedor a marisco y 
petróleo, brea y escaramujos, en los muelles de Regla, me conmovían indeciblemente, resuscitando en mi memoria decenas de personajes ausentes/ presentes ${ }^{33} . . . "$

que la brise marine intensifie et transporte jusqu'aux narines des navigateurs :

"El aire ya huele distinto - decía el Primer Magistrado sorbiendo una brisa que le traía un inequívoco aliento de lejanos manglares ${ }^{34}$."

Enfin, les rues de La Havane donnent au promeneur une telle sensation de paix et de fraîcheur que l'on croirait se trouver dans un lieu édénique :

"Pero las que nos quedan (las calles), con todo y mal trazadas como pudieron estar, nos brindan una impresión de paz y de frescor que difícilmente hallaríamos en otras ciudades ${ }^{35}$."

Mais il n'y a pas que le port ni les rues qui supposent une telle poésie. Les demeures cubaines et leur architecture pleine de cachet revêtent aussi une importance capitale aux yeux du romancier cubain qui s'attarde très souvent à nous les décrire avec force détails car elles sont un des reflets de l'évolution de la civilisation sur l'île qui permet de définir de façon explicite le concept de cubanité - ou d'identité cubaine -.

Ainsi. Carpentier nous révèle-t-il souvent l'importance et la richesse de l'ornementation des façades des vieilles demeures coloniales, la présence de grilles ouvragées qui décorent les fenêtres en rappelant les caprices d'une végétation tropicale luxuriante :

“... (las mansiones señoriales se adornaban) de mármoles preciosos y finos alfarjes de rosáceas y mosaicos - de rejas diluidas en volutas tan ajenas al barrote que eran como claras vegetaciones de hierro prendidas de las ventanas ${ }^{36}$..."

Ces grilles sont d'ailleurs d'après lui un des symboles clefs de la société cubaine puisque, comme le signale Jean Lamore, "elles ont une fonction emblématique qui permet de déterminer le statut social. »

Mais La Havane c'est surtout et avant tout peut-être la ville des colonnes. Il n'est pas une seule description de la ville révélée par Carpentier, soit dans ses essais, soit dans ses romans, qui ne rappelle leur présence et leur multitude au sein de la ville. La colonne fait partie intégrante des intérieurs des demeures cubaines mais aussi de l'ornementation extérieure de l'espace urbain. Dans La ciudad de las columnas justement, Carpentier explique ainsi l'apparition de cet élément architectural :

"La columna es elemento de decoración interior, lujo y adorno, antes de los días del siglo XIX, en que la columna se arrojara a la calle y creara una de las más singulares constantes del estilo habanero: la increíble profusión de columnas en una ciudad que es emporio de columnas, selva de columnas, columnata infinita, última urbe en tener columnas en tal demasía ${ }^{37}$."

4 Dans $E l$ acoso, l'élément colonne revient inlassablement tout au long du récit jusqu'à devenir image récurrente unique se substituant à la ville même :

"Más allá de los cuerpos, era el parque de columnas abandonadas al chaparrón ${ }^{38} . . . "$

"Eran calzadas de columnas ; avenidas, galerías, caminos de columnas, iluminadas a giorno, tan numerosas que ninguna población las tenía en tal reserva ${ }^{39} .$. ;"

“...se había arrojado a la ciudad. De sombra en sombra alcanzó el término de los árboles, pasando al mundo de las columnas. Columnas listadas de azul y de blanco ${ }^{40} \ldots "$

Dans, La consagración de la primavera, Enrique évoque immédiatement et principalement les colonnes pour décrire sa ville natale à Vera la russe : 
"Quien ahora me habla evoca la ciudad de su infancia, ciudad de muchas columnas, infinidad de columnas, columnas en tal demasía - según él - que pocas ciudades en el mundo podrían aventajarla en eso ${ }^{41}$."

Enfin dans Los convidados de plata, le récit s'ouvre par une description de La Havane qui fait là encore référence aux colonnes :

"Había algo cambiado en las energias de la ciudad que como ciudad al fin tenía sus mecanismos soterrados, acaso invisibles actuantes sobre el amasijo de casas, de palacios, de tugurios, de azoteas y columnatas que la componian ${ }^{42}$."

Et la nuit, cette profusion de colonnes, de grilles et d'ornements donne à la rue un aspect quelque peu fantastique :

“...se vio Sofia fuera, entre mansiones que la noche acrecía en honduras, altura de columnas, anchura de tejados cuyas esquinas empinaban el alero sobre rejas rematadas por una lira ${ }^{43} . . . "$

Présente à tout instant, en tout lieu, "la colonne semble modeler l'espace urbain en lui conférant volume et dynamisme. Et la réitération de la colonne comme forme récurrente qui se développe à l'infini fait de la ville des colonnes, la ville-colonne, comme le remarquent Jean Lamore et Marie-Hélène Motarella..

Mais ces colonnes, innombrables, multiples et qui donnent l'impression de se multiplier à l'infini ont une fonction qui dépasse largement le simple constat formel d'une ville dominée par un élément architectural unique. En effet, elles sont aussi avant tout, comme l'indique l'auteur lui-même, le résultat d'un esprit baroque né de la transculturation et du mélange, à travers les siècles, des styles importés et imprimées par les différentes civilisations qui se sont succédées et qui ont cohabité dans l'île :

"La multiplicación de las columnas fue la resultante de un espíritu barroco... Espíritu barroco legítimamente antillano, mestizo de cuanto se transculturizó en estas islas ${ }^{4}$."

La superposition de ces styles ont contribué au fil du temps à la création d'un style sans style qui est, selon Carpentier, l'essance même du baroque latino-américain :

“...la superposición de estilos, buenos o malos... fueron creando a La Habana ese estilo sin estilo que a lo largo, por proceso de simbiosis, de amalgama, se erige en un barroquismo peculiar ${ }^{45}$."

A plusieurs reprises, le romancier cubain s'est d'ailleurs plu à nous révéler ces styles différents qui fondent l'originalité de l'espace et de l'homme cubains :

"Columnas de medio cuerpo dórico y medio cuerpo corintio, jónicos enanos, la existencia de cierto modern styl parisiense, ciertas ocurrencias de arquitectos catalanes ${ }^{46} . . . "$

"Asomábase a la calle contemplando el mundo de casas donde, revueltos con lo californiano, gótico o morisco, se erguían partenones enanos, templos griegos de lucetas y persiana, villas renacentistas entre malangas y buganvillas, cuyos entablamentos eran sostenidos por columnas enfermas ${ }^{47}$."

Et c'est précisément ce baroque si particulier à La Havane et si caractéristique de l'île qui permet de définir l'essence même de l'identité nationale car, comme le signale Carpentier dans La ciudad de las columnas, ce mélange des styles est « une des constantes qui peut être considérée comme spécifiquement cubaine ${ }^{48}$."

Enfin nous signalerons, avec Jean Lamore et Marie Hélàne Motarella que « la colonne à Cuba en tant qu'expression d'une pratique urbanistique concrète développée par toute une société au fil des siècles a fini par définir la ville. Par ailleurs, la colonne ou les colonnes sont bien plus qu'une forme architecturale pour Carpentier; elles 
fonctionnent aussi au niveau symbolique ; elles ont une charge sémantique très forte, en ce qu'elles nous disent notre passé et celui de ceux qui nous les ont léguées ${ }^{49}$. »

51 A tout cela vient s'ajouter que les rues de La Havane peuvent aussi être, comme le signale Ojardias Khales ${ }^{50}$, l'espace de l'insolite puisque Enrique dans La consagración de la primavera contemple des vitrines où sont exposés d'étranges mariés :

“....me enternecía ante la exhibición de las posibles novias, adornadas de lazos, vestidas de ternos colores, puestos los bracitos regordetes, como de angelotes, sobre cojincillos bordados ${ }^{51}$."

Et, dans El acoso, une boutique où l'on vend des objets de sorcellerie fait face à l'église :

“Allí dormía la iglesia parroquial de un gótico yesoso... frente a la tienda de los imanes, piedras del trueno y manos de azabache para preservar a los niños de enfermedades y males de ojos ${ }^{52}$."

Dès lors le promeneur, tel Enrique dans La consagración de la primavera, ne peut ressentir face à la beauté et à l'originalité de La Havane que tout un nombre de sensations qui vont de l'émerveillement à l'attendrissement en passant par l'étonnement et l'émotion :

"Y fue mi deslumbramiento ante una ciudad re-descubierta ${ }^{53}$ "

"Me detenía, atónito, ante un viejo palacio colonial que me hablaba por todas sus piedras ${ }^{54} . . . "$

"Una repentina emoción me suspendía el resuello al sentir la llamada de una fruta $^{55} . . . "$

"El aliento de las anafes... me conmovían indeciblemente ${ }^{56}$."

Et toutes ces sensations ressenties en flânant et en parcourant à pied la capitale cubaine permettent à l'être humain de se retrouver et de prendre pleinement conscience de son essence :

"Hijo pródigo, paseaba pues por mis calles (jamás una calle de París me había dado la impresión de ser mía), hallándome a mí mismo tras de largo extravío ${ }^{57}$..."

"Y como visitante que en un vasto museo transita de cuadro a cuadro, de testero a vitrina, andaba yo por esta Habana que, de pronto, se hacía recuento de mis raíces ${ }^{58}$."

De fait, tous ces éléments développés par le romancier cubain à travers ses chroniques, ses essais et ses romans contribuent finalement à faire de La Havane une ville unique et à en faire la Ville latino-américaine par antonomase :

“...de lo abigarrado, de lo entremezclado, de lo encajado... han ido surgiendo las constantes de un empaque general que distingue a La Habana de otras ciudades del continente ${ }^{59}$."

Mais plus que Ville latino-américaine par antonomase, La Havane, « ce joyau baroque par son architecture et ses couleurs, parfaitement enchâssé dans son écrin naturel, royaume du bizarre, de l'insolite, est avant tout un exemple caractéristique de ce "réelmerveilleux" que Carpentier trouve en Amérique latine et qu'il s'attache à décrire et à universaliser ${ }^{60}$."

Dès lors, on a pleinement conscience avec Jean Lamore et Marie Hélène Motarella, que Carpentier, donne littérairement naissance à La Havane, fixe définitivement la physionomie de sa ville et contribue ainsi par les descriptions qu'il en donne à en faire une ville mythique susceptible de lever aussitôt en nous des images bien précises d'une rare beauté. 


\section{La ville nord-américaine, ou le mythe démythifié}

Située à l'opposé de ce que représente La Havane pour l'écrivain cubain, New York apparaît comme un contre-mythe puisqu'elle est l'exemple typique, archétypique de la grande métropole qui a grandi démesurément en dépit du bon sens et qui, conséquence inévitable, a entraîné la deshumanisation de l'être humain.

Aussi, si Enrique le cubain, personnage principal de La consagracion de la primavera, s'intéresse à New York c'est avant tout pour en étudier son aspect tératologique, c'està-dire ses anomalies et ses monstruosités :

"El aprendiz de arquitecto que en mí vivía se interesaba grandemente por New

York, pero más que nada por lo que llamaba su aspecto teratológico ${ }^{61}$."

Pour lui, cette métropole fournit en matière d'architecture une parfaite illustration de «tout ce qu'il ne fallait pas faire à l'avenir si l'on voulait s'en tenir au bon sens en matière d'urbanisme ${ }^{62} "$, bien qu'il reconnaisse cependant que New York possède un certain cachet en raison même de son gigantisme :

"Aquello tenía garra, atmósfera y carácter, indudablemente, pero su innegable poder de seducción le venía de lo fenomenal, tumultuoso y dsorbitado. Era urbe que sacaba de quicio ${ }^{63} . "$

Son attrait ou le charme qu'elle semble donc devoir exercer sur le narrateur qui la parcourt à pied provient, comme dans le cas de La Havane, du mélange des styles des maisons sans style qui se côtoient le long des rues de quelques quartiers :

“...en una aglomeración de construcciones dispares, de casas sin estilo y de otras que eran revoltijos de todos los estilos del pasado, alineadas por destino aleatorio a lo largo de las calles ${ }^{64}$."

Mais ici point de beauté baroque comme dans la capitale cubaine. Au contraire, en règle générale, l'architecture qu'offre la ville est plutôt nue, uniforme, sans goût aucun, à tel point que le narrateur de Los pasos perdidos ne peut même pas établir de distinctions bien précises entre une maternité et une entreprise de pompes funèbres :

"Maciza y silenciosa, la funeraria de infinitos corredores parecía una réplica en gris del inmenso hospital de maternidad, cuya fachada huérfana de todo ornamento, tenía una hilera de ventanas todas iguales ${ }^{65}$."

3 Aussi si La Havane, comme on a vu, était la belle ville des colonnes que l'on sait, New York est en revanche la ville gratte-ciel. «Véritables mausolés érigés à la gloire du Profit » comme les qualifie l'auteur, ces gratte-ciel sont la matérialisation concrète d'une urbanisation à tout crin et d'un développement gigantesque très souvent mal contrôlé. Imposante masse revêche de béton armé, d'aluminium ou de verre, le gratteciel est un bloc isolé, une "unité sans contexte, un monde à part, froid et clos, qui vient briser tout désir d'harmonie :

"Y los famosos rascacielos - a veces hermosos cuando se les consideraba como unidades sin contexto - se erguían en medio de todo ello como mundos cerrados, ufanos de sí mismos, aislados en su propia unicidad, en un en sí para sí que desconcertaba cualquier apetencia o necesidad de armonía ${ }^{66} . . . "$

Pour comble, dans sa démesure, le gratte-ciel bouche l'horizon, arrête la lumière et plonge, en plein jour, la rue dans les ténèbres. Pire encore, il enferme égoistement l'être humain dans une sorte d'univers concentrationnaire d'où toute issue sur l'extérieur est rendue impossible et où toute vélléité de communication est interdite : 
"Nada tenía este rascacielos que ver con el otro, clausurando a los humanos en sus entrañas egoístas de mundo aparte, con vías verticales de sótano a techo, cuyas calles interiores se adicionaban, unas sobre otras, sin salida posible a lo circundante ${ }^{67}$."

"No había continuidad, comunicación ni vínculos entre esas moles de concreto armado, aluminio, cristal ${ }^{68}$." un formidable contre-point par rapport à La Havane, puisqu'il semble exister entre ces deux villes la même différence qui existe entre l'enfer et le paradis. La grande métropole nord-américaine est donc bien une image «du chaos, du tourbillon, du fatras, du fouillis, du capharnaüm » comme la définit Enrique dans La consagración de la primavera et à ce titre, s'il ne lui est pas forcément impossible d'accéder au rang de mythe, à l'évidence il s'agit pour Carpentier d'un contre-mythe ou d'un mythe nettement négatif ou du moins rendu tel. 


\section{La ville européenne : grandeur et décadence ou la progressive destruction du mythe}

71 Jean Lamore et Marie Hélène Motarella rappellent que «la tâche assignée par Carpentier au romancier est complexe car en même temps qu'il doit révéler la ville, c'est-à-dire en dévoiler les réalités préexistantes et sous-jacentes, il doit aussi fixer une image de la ville parce que face aux Bruges, Venise, Rome, Paris, Dublin de la littérature européenne, aucune ville américaine n'a été mythifiée au point d'éveiller immédiatement des connotations bien déterminées ${ }^{75}$. "

72 Dès lors, un des propos du romancier cubain va être de donner dans ses romans une image négative des villes européennes afin de permettre aux villes de l'Amérique latine d'entrer dans le concert universel des grandes villes et de devenir mythes urbains en surpassant les anciens mythes européens.

73 Carpentier choisit la plupart du temps comme point de référence les capitales des pays d'Europe, puisqu'elles sont le lieu où s'incrit l'image même du pays dans sa globalité. Ainsi, Madrid apparaît-elle comme une métropole triste, pauvre, sale et sans éclat :

"Era triste, deslucida y pobre. Fuera de la Plaza Mayor todo era aquí angosto, mugriento y esmirriado cuando se pensabe en la anchura y el adorno de las calles de allá ${ }^{76} . "$

et dont les monuments et l'architecture font davantage penser à un décor de vaudeville qu'à la capitale de l'Espagne :

"Madrid era cosa de género chico, con sus puestos de agua, azucarillos y aguardiente, sus serenos, y sus tertulias de cafép ${ }^{77} . . . "$

Berlin est une capitale sans cachet, à l'architecture lourde et à la population mal dégrossie :

"Berlin era ciudad que no había usurpado su nombre primitivo de "lugar de osos", con la pesadez arquitectónica de su puerta de Brandemburgo. semejante a una locomotora de granito ${ }^{78}$."

76 Vienne est tout au plus une bourgade provinciale qui usurpe son titre de capitale d'Autriche :

"Viena, pese a una fama de elegancia y voluptuosidad debida a la opereta y a los valses, era, en realidad, terriblemente provinciana con sus oficialillos sacados de tintorería, sus diez o doce restaurantes ansiosos de parecerse a los de acá (París), tras de un Danubio café-con-leche que sólo se azulaba algún día 29 de año bisiesto ${ }^{79}$."

Berne est le prototype même de la cité ennuyeuse envahie par des baromètres et des thermomètres :

"Berna, burgo tiedoso. con sus estatuas de heraldos helvetas en medio de calles... era un vasto muestrario de relojes y barómetros ${ }^{80}$."

Rome, la ville aux mille cloches, aux maisons grandes ouvertes et aux marbres resplandissant sous le soleil est avant tout une ville aux ruelles humides souillées par toute sorte d'immondices :

"Su aparición en las callejas populares - húmedas de ropas tendidas, sucias de repollos, piltrafas y borra de café - había promovido un verdadero alboroto ${ }^{81}$." 
du carton-pâte, de l'illusion et du trompe-l'œil :

"En Roma, cada plaza, cada bocacalle, era un escenario de ópera ${ }^{82 "}$

Venise enfin, mythe parmi les mythes littéraires et universels, accuse aux yeux de Carpentier une décadence telle qu'elle finira selon lui par être engloutie dans ses eaux fangeuses, image extrême de la perte de l'hégémonie mythique du Vieux Continent au profit de mythes nouveaux surgis en Amérique latine :

"Venecia parecía hundirse de hora en hora en sus aguas turbias y revueltas. Una gran tristeza se cernía sobre la ciudad enferma y socavada ${ }^{83}$."

81 Seule la capitale française, Paris, trouve quelque grâce aux yeux du romancier cubain, peut-être parce qu'elle fut la ville qui l'accueuillit en exil en 1927 et qu'il fréquenta assidûment quand il occupait le poste d'attaché culturel à l'ambassade de Cuba. Ces séjours prolongés dans la capitale devaient d'ailleurs lui inspirer un grand nombre de chroniques $^{84}$.

Paris, ville lumière, ville phare du Siècle des Lumières est pour Carpentier, la ville emblématique de la Révolution, des Idées et des idéaux. Dans son roman El siglo de las luces, il évoque avec sympathie la transformation de la rue parisienne lors des événements de 1789 :

"La Revolución había infundido una nueva vida a la Calle - a la Calle de enorme importancia para Esteban ya que en ella vivía y desde ella contemplaba la Revolución ${ }^{85} . "$

83 C'est aussi une terre promise où règnent en maître l'intelligence, la culture, la tolérance et le respect des droits de l'homme. A plusieurs reprises Carpentier a insisté sur ces notions qui font et fondent l'essence même de la capitale française. Dans El reino de este mundo, la troupe de théâtre arrivée dans l'île d'Haïti vient de Paris :

"M. Lenormand de Mézy se hacía llevar cada vez más a menudo al teatro del Cabo, donde verdaderas actrices de París cantaban arias de Juan Jacobo Rousseau ${ }^{86}$;"

Dans El recurso del método, le Premier Magistrat reconnaît sans détour que :

"París en cambio era Tierra de Jauja y Tierra de Promisión, Santo Lugar de la Inteligencia. Metrópoli del Saber Vivir, Fuente de Toda Cultura ${ }^{87}$."

Cette importance de la culture que tous semblent reconnaître à la capitale française fait de Paris une ville mythique, une ville sacralisée :

“...los Rubén Darío, Gómez Carrillo. Amado Nervo, y tantos otros latinoamericanos que de la Ciudad Mayor habían hecho, cada cual a su manera, una suerte de Ciudad de Dios $^{88}$."

Dans Concierto barroco, le noir cubain Filomeno explique que Paris est la seule ville européenne qui, au début du XX⿳亠㐅八me siècle, concède aux artistes noirs - à l'image de Joséphine Baker et de Louis Armstrong - un droit de cité et qui surtout les considère, les respecte et leur offre même un certain nombre de privilèges alors totalement inconcevables à La Havane.

“¿ Cuando volverás a tu país. ? No lo sé ; por lo pronto iré a París. ¿ Las hembras? $¿$ la torre Eiffel ? No hembras hay en todas partes. Y la torre Eiffel ha dejado desde hace tiempo de ser un portento. Asunto para pisapapel si acaso.

¿ Entonces ? En París me llamarán Monsieur Philomène así con PH. En La Habana sólo sería el negrito Filomeno ${ }^{89}$." 
87 C'est que Paris a toujours été aux yeux de Carpentier une terre d'asile qui permet notamment aux exilés de s'intégrer plus ou moins facilement au sein de la population française :

"Y eran numerosísimos los estudiantes cubanos que ahora se encontraban en París por huir de la represión machadista o tratando de proseguir sus estudios interrumpidos ${ }^{90} . . . "$

Cette intégration est d'ailleurs facilitée par le fait que la Ville Lumière, très animée et fort joyeuse, est un formidable creuset cosmopolite qui fait preuve d'un certain syncrétisme en matière d'art et de pensée puisqu'elle est ouverte à toutes les influences venues de l'extérieur :

"París, según afirmaba ahora el Ilustre Académico, se iba pareciendo a la Roma de Heliogábalo, que abría sus puertas a cuanto fuese raro, dislocado, siriaco, bárbaro, primitivo. Los escultores modernos, en vez de inspirarse en los grandes estilos se pasmaban ante lo miceniano, lo pre-helénico, lo escita, lo estepario. Había gente, en estos días, que coleccionaban máscaras africanas, figuras erizadas de clavos votivos, ídolos zoomorfos... De los Estados Unidos nos venían músicas de negros. Un escandaloso poeta italiano había llegado a publicar un manifiesto donde se proclamaba la necesidad de acabar con Venecia e incendiar el Louvre ${ }^{91}$."

Par ailleurs, Paris - et son emblématique Arc de Triomphe - est la ville des plaisirs : promenades le long des boulevards à l'ombre des arbres centenaires, dégustation de quelques bonnes bières renommées dans les bistrots typiques, étourdissement dans les boîtes de nuit à la mode et enfin plaisirs des sens savamment prodigués par les dames de certains bordels.

"Volvían los recién llegados al ritmo de tantos y tantos despreocupados paseos que, según fuese el antojo, podían llevarlos de La Chope du Pantheon a los bulbos de tulipanes del Quai de la Mégisserie ${ }^{92}$."

"Y el Primer Magistrado, seguido de su secretario, entró en el conocido bistrot de flamenco ambiente ${ }^{93}$..."

La capitale française apparaît aussi souvent comme un lieu où durant ses flâneries le promeneur peut s'émerveiller parce que la ville présente un caractère singulier, imprévu et parfois comique. Esteban, dans El siglo de las luces, est ainsi fasciné par les cafés décorés à la manière chinoise, les funambules qui imitent en plein air les acrobaties d'artistes fameux et le tondeur de chiens qui a dressé boutique sur les rives du fleuve :

“Todo le era espectáculo bueno para detenerse y admirarse : el café era decorado a la manera china... Los funámbulos que al aire libre remedaban las suertes de acróbatas famosos y el atusador de perros que había instalado su oficina en las orillas del río. Todo era singular, imprevisto, gracioso ${ }^{94}$..."

91 Même Enrique dans La consagración de la primavera avoue qu'il n'a pas pu résister au charme offert par les lieux symboliques de Paris, bien qu'il déclare qu'il a eu la sensation de se sentir totalement étranger à la ville :

“Aunque parezca raro, no es París, para mí, esa especie de cuna a la que siempre se regresa por los universales caminos de la cultura... Se dijo que aquí nadie podía sentirse del todo forastero. Pero el hecho es que me sentía tremendamente forastero ${ }^{95} . . . "$

"En París empecé, desde luego, a maravillarme ante todo lo maravilloso, yendo de Santo Lugar de la Fe a Santo Lugar de la Cultura, de Santo Lugar de la Poesía a Santo Lugar de la Revolución, en necesario, justo y ferviente peregrinar ${ }^{96}$." 


\section{d'étonnement celui qui sait la découvrir :}

"Pero, después de mucho andar de gárgolas medievales a entablamentos de Mansard, de la Place des Vosges a la serena grandeza del Domo de los Inválides, majestuosamente asentado en sus nobles y serenas columnas, después de ir de tumbas ilustres a campanarios de alta jerarquía, empecé, al azar de interminables caminatas, a descubrir lo que. de la ciudad, no se decía en guías... Y entonces se me fue revelando una ciudad singular, ignorada cuyas extravagancias me llenaron de sorpresa ${ }^{97}$."

Ce caractère insolite de la Ville Lumière provient tout d'abord de ses balcons au charme un peu désuet qu'Enrique découvre et décrit en se promenant dans ses rues. De ce fait, si La Havane est la ville des colonnes et New York la ville gratte-ciel, Paris peut être définie comme la ville des balcons :

"Para empezar París era La-Ciudad-de-los-Balcones-Desiertos. Ninguna capital del mundo, creo yo, cargaba con tal peso de herrajes inútiles, puestos en balcones cortos, largos, corridos, esquineros, modestos, pomposos, clásicos, fantasieros, alardosos, de buen estilo, de mal estilo, abiertos en entresuelos o perdidos en pisos cimeros o vecinos del asfalto o difuminados por las brumas mañaneras, múltiples, tan incontables como lo eran las columnas de La Habana, con algo, según los casos, de cátedra, de púlpito, de galería para asistir a un desfile real, pero balcones al fin, balcones, balcones, más balcones, de Auteuil a Vincennes, de la Puerta de Clignancourt a la de Orléans, en torno a l'Etoile, frente al Elysée, a lo largo del Boulevard Saint Michel, de la Avenue Kleber, proliferantes, vertiginosos, minúsculos o encumbrados, asimétricos o desgarbados, empinados, modestos o nuevorricos - balcones, balcones, más balcones, pero con la particularidad de que jamás, en estío como en invierno, dibujábase, tras de sus barandas, una forma humana. Me preguntaba para qué servían esos balcones, si nadie se asomaba a ellos ${ }^{98}$."

Et à l'étonnement succède la stupeur quand il remarque les monstruosités architecturales dues à un individualisme esthétique outré qui, négligeant de se préoccuper de ce qui se trouve à côté, fait se juxtaposer dans une rue proche de l'Etoile, les édifices de style les plus variés :

"Pero esa extravagancia de los balcones desiertos no era la única que advenía yo en una ciudad que encerraba verdaderos monstruos arquitectónicos, nacidos tras de los feroces desmontes y desbastes urbanísticos del Segundo Imperio y que revelaban, en ciertas edificaciones de comienzos de este siglo, un individualismo estético tan increíble, tan totalmente despreocupado de lo que hubiese al lado, que. en ochenta metros de una quieta calle del barrio de l'Etoile había visto yo con estupor, construidos de pared a pared, hombro con hombro, un palacio bizantino, un castillo a lo Chambord. un hôtel particulier de macarronadas novecentistas. una residencia gótica y una villa romana $a^{99}$."

Enfin, il voit une autre ville, inutile et chaotique, superposée à la ville même : celle des toits de Paris, au niveau des mansardes:

"Y había, sobre todo, una inmensa ciudad inútil, caótica, invisible, puesta sobre la ciudad, ciudad sobre ciudad, que. de repente, junto a las pétreas garitas, balaustradas, barroquismos cimeros del Hotel Lutetia, en torno al art-nouveau del inmueble Berlitz, revelaba, a quien tuviese acceso a tales niveles, que allá arriba, entre mansardas, techos de color plomo y cuartos de criadas, toda una Pompeya ahumada y llovida se desplegaba, ignota, en medio de chimeneas de metal gris... Sobre sextos, séptimos pisos, allí donde en buhardillas hervía la sopa de coles en reverberos de alcohol, donde toda una miseria ancilar se ocultaba bajo mantas agujereadas o se ayuntaba en camastros de hierro, había escondidos Jardines 
Colgados, terrazas, pasarelas, puentes, escalerillas al borde de patios abisales, foros enanos, cortijos normandos, nunca vista por la humanidad que abajo se afanaba entre los paraderos de autobuses y las entradas modem-style de los trenes subterráneos... ${ }^{100} . . . "$

Paris, capitale universelle de la culture et du syncrétisme artistique, est donc pour Alejo Carpentier une ville où il fait bon vivre, où la culture justement, le savoir-vivre et la beauté ont contribué à en faire un mythe universel qui n'a jamais cessé de fasciner et d'attirer; enfin, elle lui apparaît comme une ville faite de plusieurs villes où règnent l'insolite et l'étrange. Après La Havane, c'est certainement l'espace urbain pour lequel il a toujours conservé une grande sympathie même si elle a toujours été associée dans son esprit à une ville d'exil - "jamás una calle de Paris me había dado la impresión de ser mía. dira Enrique dans La consagración de la primavera - et si dans le dernier chapitre de El recurso del método il en fait une cité moderne décevante, poursuivant ainsi sa tâche de destruction des mythes européens.

\section{Conclusion}

Carpentier, en proposant une vision plutôt négative des grands espaces urbains européens et américains, parvient à créer le mythe - nouveau - de la ville latinoaméricaine en prenant comme point de référence La Havane, dont il valorise nécessairement les éléments symboliques qui la caractérisent. Sa ville natale, à présent capable de faire lever chez le lecteur des images bien précises, peut entrer dans le concert des grandes villes universelles et même les surpasser grâce à sa singulière beauté. Et on peut finalement affirmer qu'Alejo Carpentier, après avoir solidement établi les bases d'une poétique des contextes urbains latino-américains, a ouvert la voie à une littérature continentale qui s'est davantage intéressée à la ville, et notamment à La Havane si l'on songe à des écrivains comme Severo Sarduy, Reinaldo Arenas, Guillermo Cabrera Infante, Virgilio Piñera, Hector Padilla, Lydia Cabrera et Zoe Valdés.

\section{NOTES}

1. Alejo Carpentier, La novela hispanoamericana en víspera de un nuevo siglo y otros ensayos, México, Siglo XXI, 1981, p. 14.

2. Alejo Carpentier, "Conciencia e identidad de América latina", in, La novela hispanoamericana en víspera de un nuevo siglo y otros ensayos op. cit., p. 79-80.

3. Alejo Carpentier, "Problemática de la actual novela latinoamericana", in Tientos y Diferencias, México, Universidad Nacional Autónoma de México, 1963, p. 13.

4. Ibid., p. 12.

5. Ibid.

6. Ibid., p. 13.

7. Ibid.

8. Alejo Carpentier, La novela hispanoamericana en víspera de un nuevo siglo..., op. cit., p. 14.

9. Ibid., p. 14 . 
10. Ibid., p. 15.

11. Ibid., p. 13.

12. Alejo Carpentier, "Problemática actual de la literatura", in Tientos y Diferencias, op. cit.. p. 15.

13. Jean Lamore \& Marie Hélène Motarella, « La ville selon Carpentier : révélation et lecture », in Hommage à Alejo Carpentier. Bordeaux, PUB, 1985, p. 148.

14. Anny Ojardias Khales, Le temps et l'espace dans l'œuvre romanesque d'Alejo Carpentier, Paris, 1979, Thèse de 3ème cycle, p. 42.

15. Alejo Carpentier, Los pasos perdidos, México, Distribución iberoamericana de Publicación, 1953, p. 42.

16. Alejo Carpentier, El recurso del método, México, Siglo XXI, 1974, p. 151.

17. Ibid., p. 151.

18. Alejo Carpentier, El reino de este mundo, México, Distribución iberoamericana de Publicación, 1949 , p. 45.

19. Alejo Carpentier, La consagración de la primavera, México, Siglo XXI, 1978, p. 441.

20. Alejo Carpentier, "Divagaciones urbanas", in El País, La Habana, 24 de julio de 1925 ; "La Habana vista por un turista cubano", in Carteles, Cuba, $\mathrm{n}^{\circ} 41,43,45,49 \& 50$, del 8 de octubre de 1939 al 17 de diciembre de 1939 ; "Los muelles de La Habana", in Información, La Habana, 22 de julio de 1944 ; "Las casas de antaño", in Información, La Habana, 9 de agosto de 1944.

21. Les romans El acoso. El siglo de las luces, La consagración de la primavera ont pour cadre La Havane. Mais la capitale cubaine apparaît aussi dans El recurso del método, Concierto barroco, El derecho de asilo. Los fugitivos. Oficio de tinieblas et Viaje a la semilla.

22. Alejo Carpentier, "Problemática de la actual novela latinoamericana", in Tientos y Diferencias, op. cit., p. 14.

23. Ibid.. p. 13.

24. Jean Lamore \& Marie Hélène Motarella, «La ville selon Carpentier : révélation et lecture » in Hommage à Alejo Carpentier, op. cit., p. 149.

25. Alejo Carpentier, "La ciudad de las columnas", in Tientos y Diferencias, op. cit., p. 51.

26. Alejo Carpentier. El siglo de las luces, México, Siglo XXI, 1962, p. 9.

27. Alejo Carpentier, "Los muelles de La Habana", in Información, op. cit.

28. Alejo Carpentier, El siglo de las luces, op. cit., p. 300.

29. Ibid.

30. Alejo Carpentier. El acoso, México, Compañía general, 1956, p. 60.

31. Alejo Carpentier, El siglo de las luces, op. cit., p. 10.

32. Ibid., p. 10.

33. Alejo Carpentier, La consagración de la primavera, op. cit., p. 202.

34. Alejo Carpentier, El recurso del método, op. cit., p. 42.

35. Alejo Carpentier, "La ciudad de las columnas", in Tientos y diferencias, op. cit., p. 52.

36. Alejo Carpentier, El siglo de las luces, op. cit., p. 10.

37. Alejo Carpentier, La ciudad de las columnas, op. cit., p. 54.

38. Alejo Carpentier. El acoso, op. cit., p.10.

39. Ibid., p.39.

40. Ibid., p. 60.

41. Alejo Carpentier, La consagración de la primavera, op. cit., p. 31.

42. Alejo Carpentier, Los convidados de plata. Montevideo, Sandino, 1972, p. 5.

43. Alejo Carpentier, El siglo de las luces, op. cit., p. 300.

44. Alejo Carpentier, La ciudad de las columnas, op. cit., p. 61.

45. Ibid., p. 52.

46. Ibid., p. 54.

47. Alejo Carpentier, El acoso, op. cit., p. 39.

48. Alejo Carpentier, La ciudad de las columnas, op. cit., p. 54 
49. Jean Lamore \& Marie Hélène Motarella, « La ville selon Carpentier : révélation et lecture », in Hommage à Alejo Carpentier, op. cit.. p. 149.

50. Anny Ojardias Khales, Le temps et l'espace dans l'œuvre romanesque d'Alejo Carpentier, op. cit., p. 53.

51. Alejo Carpentier, La consagración de la primavera, op. cit., p. 202.

52. Alejo Carpentier, El acoso, op. cit., p. 48.

53. Alejo Carpentier, La consagración de la primavera, op. cit., p. 203.

54. Ibid.

55. Ibid.

56. Ibid.

57. Ibid., p. 53.

58. Ibid., p. 204.

59. Alejo Carpentier, "La ciudad de las columnas", in Tientos y Diferencias op. cit., p. 52.

60. Anny Ojardias Khales, Le temps et l'espace dans l'œuvre romanesque d'Alejo Carpentier. op. cit., p. 50.

61. Alejo Carpentier, La consagración de la primavera, op. cit., p. 270.

62. Ibid.

63. Ibid.

64. Ibid.

65. Alejo Carpentier. Los pasos perdidos, op. cit., p. 15

66. Alejo Carpentier, La consagración de la primavera, op. cit., p. 270.

67. Ibid.

68. Ibid.

69. Ibid.

70. Ibid., p. 271.

71. Ibid., p. 270.

72. Ibid.

73. Ibid.

74. Ibid., p. 272.

75. Jean Lamore et Marie Hélène Motarella, « La ville selon Carpentier : révélation et lecture », in Hommage à Alejo Carpentier, op. cit., p. 147.

76. Alejo Carpentier, Concierto barroc, México, Siglo XXI, 1974, p. 27.

77. Alejo Carpentier. El recurso del método, op. cit., p. 94.

78. Ibid.. p. 85 .

79. Ibid.

80. Ibid.

81. Alejo Carpentier, El reino de este mundo, op. cit., p. 126.

82. Alejo Carpentier, El recurso del método, op. cit., p. 85.

83. Alejo Carpentier, Concierto barroco, op. cit., p. 80.

84. Alejo Carpentier, "Rincones de París que no conocen los turistas", in Carteles, La Habana. $\mathrm{n}^{\circ}$ 12. 14 de diciembre de 1928 ; "Las aldeas de París", in Carteles. La Habana, n 15, 18 de mayo de 1930 ; “Los paisajes de París", in Carteles, La Habana, n 17. 13 de diciembre de 1931 ; "Panorama en París en 24 horas", in Carteles, La Habana. n²3. 10 de marzo de 1935 : "La ciudad inmutable", in Letra y Solfa, El Nacional, Caracas, 16 de abril de 1958.

85. Alejo Carpentier, El siglo de las luces, op. cit., p. 90.

86. Alejo Carpentier, El reino de este mundo, op. cit., p. 46.

87. Alejo Carpentier, El recurso del método, op. cit., p. 96.

88. Ibid.

89. Alejo Carpentier, Concierto barroco, op. cit., p. 79.

90. Alejo Carpentier, La consagración de la primavera, op. cit., p. 78. 
91. Alejo Carpentier, El recurso del método, op. cit., p. 24.

92. Alejo Carpentier, El recurso del método, op. cit., p. 92.

93. Ibid., p. 91.

94. Alejo Carpentier, El siglo de las luces, op. cit., p. 90.

95. Alejo Carpentier, La consagración de la primavera, op. cit., p. 67.

96. Ibid.

97. Ibid., p. 68.

98. Ibid.

99. Ibid., p. 68-69.

100. Ibid., p. 69.

\section{AUTEUR}

\section{FABRICE PARISOT}

Université de Nice Sophia Antipolis 